\title{
Atomic data from the Iron Project. XVIII. Electron impact excitation collision strengths and rate coefficients for Fe III ${ }^{\star}$
}

\author{
Hong Lin Zhang \\ Department of Astronomy, The Ohio State University, Columbus, OH 43210, U.S.A. \\ Internet: zhang@payne.mps.ohio-state.edu \\ Received January 17; accepted February 27, 1996
}

\begin{abstract}
Collision strengths and maxwellian averaged rate coefficients have been calculated for 23871 transitions among 219 fine structure levels, dominated by configurations $3 \mathrm{~d}^{6}, 3 \mathrm{~d}^{5} 4 \mathrm{~s}$, and $3 \mathrm{~d}^{5} 4 \mathrm{p}$ in Fe III. Collision strengths are calculated using the $R$-matrix method with a 83 term close-coupling target expansion and for electron energies up to 10 rydbergs. Rate coefficients are tabulated at a wide range of temperatures at which Fe III is abundant in plasma sources. A brief discussion of the calculations and sample results are given. The present rates for Fe III are expected to find applications in spectral diagnostics of a variety of astrophysical sources.
\end{abstract}

Key words: atomic data — atomic processes

\section{Introduction}

Fe III emission lines are observed from many classes of astronomical objects such as H II regions, active galactic nuclei, and the Sun. Electron-impact excitation collision strengths and rate coefficients are needed for spectral analysis and diagnostics for these astronomical sources. Earlier works on electron impact excitation collision strengths in Fe III are by Garstang et al. (1978), who included the lowest five LS terms $3 d^{6}\left(a^{5} \mathrm{D}, a^{3} \mathrm{H}, \mathrm{a}^{3} \mathrm{P}, \mathrm{a}^{3} \mathrm{~F}, \mathrm{a}^{3} \mathrm{G}\right)$ in a nonrelativistic (hereafter NR) calculation, and by Berrington et al. (1991), who included the 17 levels corresponding to these five terms in a relativistic Breit-Pauli (hereafter BP) $R$-matrix calculation. The present work is a large-scale calculation involving 219 fine structure levels corresponding to $83 L S$ term target expansion dominated by configurations $3 \mathrm{~d}^{6}, 3 \mathrm{~d}^{5} 4 \mathrm{~s}$ and $3 \mathrm{~d}^{5} 4 \mathrm{p}$ (Nahar \& Pradhan 1994).

Owing to the complexity of Fe III and limitation of the current computational resources, it is necessary to make a choice between a large target expansion in the NR close-coupling calculations in order to include expected large resonance and coupling effects, and a much smaller target expansion in the BP close-coupling calculations to account for the relativistic effects. In our earlier work on Fe III (Zhang \& Pradhan 1995a, hereafter ZP1) using the close-coupling $R$-matrix method, we stud-

\footnotetext{
${ }^{\star}$ Table 2 for complete data for the Fe III is only available in electronic form at the CDS via anonymous ftp 130.79.128.5
}

ied the collision strength and maxwellian-averaged collision strength results for some forbidden transitions between the lowest levels with a seven-term NR calculation $\left(3 \mathrm{~d}^{6}\right.$ configuration), a corresponding 23-level relativistic $\mathrm{BP}$ calculation, and an 83-term NR calculation (83CC). It was concluded that the relativistic effects are small for these forbidden transitions between the low-lying levels, and that the resonances and the coupling effects arising from a large coupled-channel wavefunction expansion dominate the collision strengths in Fe III. It was also noted in that study (ZP1) that, although the relativistic effects affect the intercombination transitions the most because of their intermediate coupling with the strong optically allowed transitions (Zhang \& Pradhan 1995b), it is expected the effects would still be negligible for near neutral Fe III, based on a study of the term coupling coefficients which indicate the small extent of the relativistic coupling in the 23-level BP calculations. Therefore, in the present work, we carry out the $83 \mathrm{CC} \mathrm{NR}$ calculations, including fine structure by using algebraic recoupling, since it is impractical to include all 219 levels in relativistic BP calculations with presently available computational resources.

In this NR algebraic recoupling approach employed in the present work, the reactance matrix (the $K$-matrix) necessary for calculating the collision strengths is obtained by different stages of the NR (LS coupling) $R$-matrix package. The $K$-matrix is subsequently transformed from LS coupling to pair coupling (Eissner et al. 1974), using the 
STGFJ code which is an extension of the asymptotic region code, STGF, of the NR $R$-matrix codes (Hummer et al. 1993). Collision strengths are calculated for all 23 871 transitions between the 219 fine structure levels corresponding to the $83 \mathrm{LS}$ terms in the target expansion for electron energy range 0 to 10 rydbergs. The maxwellianaveraged rate coefficients or effective collision strengths, $\Upsilon$, are also calculated and tabulated for temperature range 1000 to $100000 \mathrm{~K}$. This is expected to cover the temperatures at which Fe III is most abundant in astrophysical sources. A brief description of the computations and the results are given in the following sections.

\section{Atomic calculations}

As mentioned above, the target expansion for the present calculations consists of the 83 LS-terms dominated by the configurations $3 \mathrm{~d}^{6}, 3 \mathrm{~d}^{5} 4 \mathrm{~s}$ and $3 \mathrm{~d}^{5} 4 \mathrm{p}$. The 83 LS terms and their observed term energies are tabulated in Table 2 of ZP1. For convenience, the 219 fine structure levels formed by these 83 terms, and their observed energies (Sugar \& Corliss 1985), are listed in Table 1. This table also provides the key to the level indices for transitions in tabulating the maxwellian-averaged collision strengths.

The collision strengths were calculated for a large number of electron energies ranging from 0 to 10 rydbergs. The choice of the energy range is made carefully in order to obtain detailed collision strengths in the region where they are dominated by resonances, as well as in an extended region where resonances are not important or have not been included, but which is necessary for an accurate calculation of the maxwellian averaged values, particularly for dipole allowed transitions.

In order to delineate the resonance structures, an effective quantum number mesh ( $\nu$-mesh) was used to obtain the collision strengths at 5280 energy points in the range $E=0-1.127$ rydbergs. The advantage of a mesh with a constant interval in effective quantum number $\nu=z / \sqrt{|E|}$, vs. a constant energy interval, is that the resonances corresponding to increasing values of $\nu$ become narrower in energy but are still resolved with the same precision (Hummer et al. 1993). However, the calculations need to be carried out at a large number of energies. This $\nu$-mesh in this energy range yields not only detailed resonance structures for transitions between the levels of lowlying terms, such as $\mathrm{a}^{5} \mathrm{D}, \mathrm{a}^{3} \mathrm{P}, \mathrm{a}^{3} \mathrm{H}, \mathrm{a}^{3} \mathrm{~F}$ and $\mathrm{a}^{3} \mathrm{G}$, but also for transitions from these levels to higher levels. The near threshold resonance structures in the collision strengths for optically allowed transitions, namely for transitions from the levels of the lower even-parity levels of $3 \mathrm{~d}^{6}$ to the odd-parity levels of the terms dominated by $3 \mathrm{~d}^{5} 4 \mathrm{p}$, such as $\mathrm{z}^{5} \mathrm{P}^{\circ}, \mathrm{z}^{5} \mathrm{G}^{\circ}$ and $\mathrm{z}^{5} \mathrm{H}^{\circ}$, are also resolved.

In the higher energy region $E>1.127$ rydbergs, the collision strengths were calculated for 14 additional energy points up to 10 rydbergs. A practical reason for terminating the $\nu$-mesh at 1.127 rydbergs is that it would take considerably more computing time and memory resources, owing to a large number of additional channels that become open at higher energies. When channels associated with the high-lying odd parity terms with $E>1.127$ rydbergs are open, the resonances for excitation to levels of these terms are not important since most transitions are optically allowed.

At low impact-electron energies, especially for the forbidden transitions between the low-lying levels in this Fe III case, contributions to the collision strength from $J \pi$ total symmetries with small $J$ are dominant and those from symmetries with large $J$ are negligible. Therefore, for $E=0-1.127$ rydbergs, we calculated partial wave contributions from total angular momenta of the electron plus target system $J=1 / 2-13 / 2$ (where $\mathbf{J}=\mathbf{L}+\mathbf{S} ; \mathbf{L}$ and $\mathbf{S}$ are total orbital and spin angular momenta). For higher energies $E>1.127 \mathrm{Ry}$, collision strengths were calculated for $J$ up to $21 / 2$. Test results show that contributions from $J=15 / 2-21 / 2$ for the forbidden transitions between the low-lying levels dominated by configurations $3 \mathrm{~d}^{6}$ and $3 \mathrm{~d}^{5} 4 \mathrm{~s}$ are negligible, while their contributions to the optically allowed transitions are pronounced but not dominant (and are also negligible for lower energies). The corresponding $S L^{\prime}$ s (for both even and odd parities) included are

$$
\begin{aligned}
& 0 \leq L \leq 11,(2 S+1)=2 \\
& 0 \leq L \leq 15,(2 S+1)=4 \\
& 0 \leq L \leq 14,(2 S+1)=6 \\
& 0 \leq L \leq 10,(2 S+1)=8
\end{aligned}
$$

As in the Fe II work (Zhang \& Pradhan 1995c), Coulomb-Bethe approximation was employed to account for the large $\ell$ contributions to collision strengths for optically allowed transitions for energies greater than 1.127 rydbergs. The electric dipole oscillator strengths required for the Coulomb-Bethe approximation were obtained by Nahar \& Pradhan (1996, the accompanying Paper XVII).

\section{Results}

In this section we present a few results for the collision strengths and tabulate a brief sample of the maxwellianaveraged collision strengths. Comparisons of the present collision strength results for some transitions with the relativistic BP results, as well as with the results by Berrington etal. (1991), were given in ZP1. These include the transitions from the ground level $3 \mathrm{~d}^{6}{ }^{5} \mathrm{D}_{4}$ to $3 \mathrm{~d}^{6}{ }^{5} \mathrm{D}_{3,2,1,0}$ (Figs. 1 and 2 in $\mathrm{ZP} 1$ ), and the transitions $3 \mathrm{~d}^{6}{ }^{3} \mathrm{H}_{6}-3 \mathrm{~d}^{6}{ }^{3} \mathrm{G}_{5}$ and $3 \mathrm{~d}^{6}{ }^{3} \mathrm{H}_{4}-3 \mathrm{~d}^{6}{ }^{3} \mathrm{G}_{3}$ (Figs. 3 in $\mathrm{ZP} 1$ ).

From Fig. 1 of $\mathrm{ZP1}$, which compares the collision strengths for the transitions $3 \mathrm{~d}^{6}{ }^{5} \mathrm{D}_{4}-3 \mathrm{~d}^{6}{ }^{5} \mathrm{D}_{3,2,1,0}$ by a seven-term 23-level BP calculation and by a seven-term NR calculation, it is seen that the relativistic effects are not important. In contrast, Fig. 2 in ZP1 for these same 


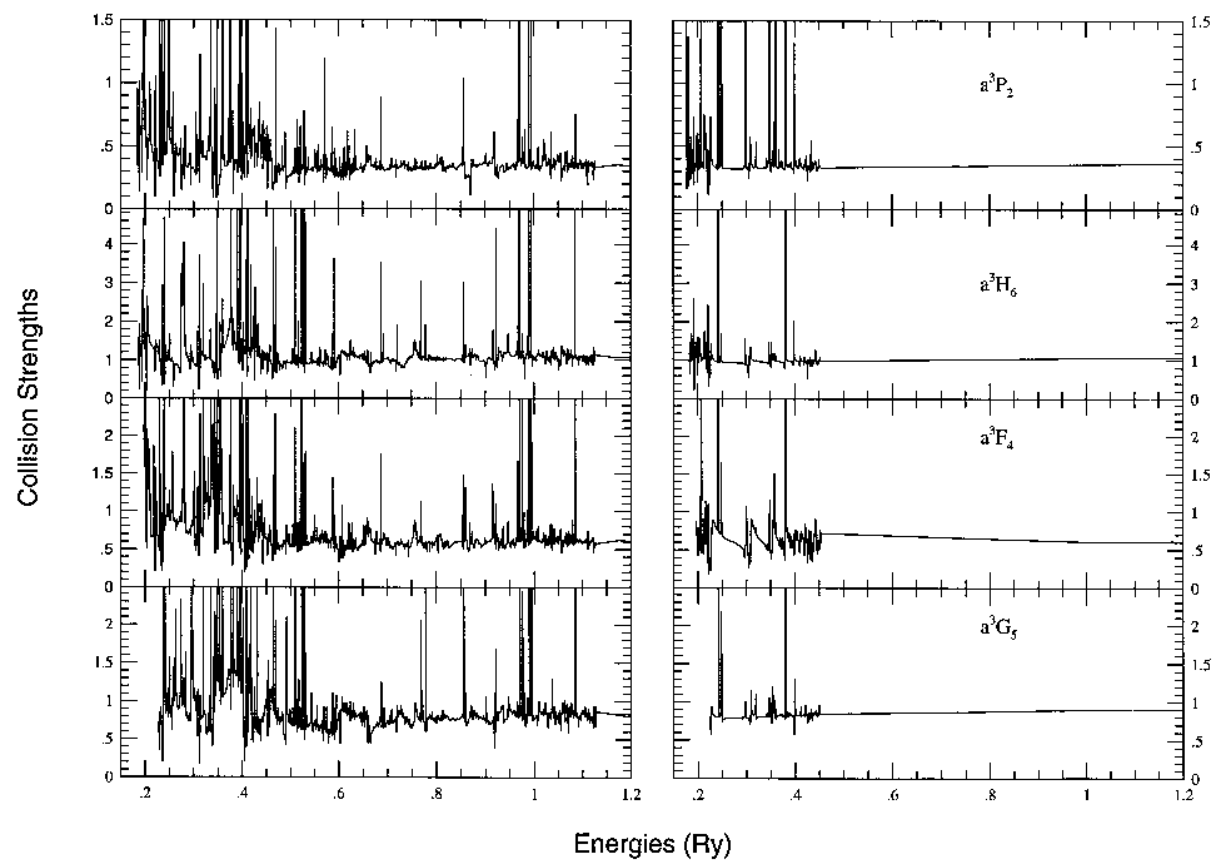

Fig. 1. The collision strengths for the forbidden transitions from the ground level $3 \mathrm{~d}^{6}{ }^{5} \mathrm{D}_{4}$ to $3 \mathrm{~d}^{6}{ }^{3} \mathrm{P}_{2}, 3 \mathrm{~d}^{6}{ }^{3} \mathrm{H}_{6}, 3 \mathrm{~d}^{6}{ }^{3} \mathrm{~F}_{4}$ and $3 \mathrm{~d}^{6}{ }^{3} \mathrm{G}_{5}$ by the $83 \mathrm{CC}$ NR calculations (left) and by the 23-level BP calculation (right, see Zhang \& Pradhan 1995a)

transitions shows that the $83 \mathrm{CC}$ NR calculations give many more resonance structures and these enhance the effective collision strengths, as seen from Table 3 in ZP1.

Here in Fig. 1 we present a comparison of the collision strengths for the transitions from the ground level $3 \mathrm{~d}^{6}{ }^{5} \mathrm{D}_{4}$ to $3 \mathrm{~d}^{6}{ }^{3} \mathrm{P}_{2}, 3 \mathrm{~d}^{6}{ }^{3} \mathrm{H}_{6}, 3 \mathrm{~d}^{6}{ }^{3} \mathrm{~F}_{4}$ and $3 \mathrm{~d}^{6}{ }^{3} \mathrm{G}_{5}$ by the $83 \mathrm{CC}$ NR calculations (left) and by the 23-level BP calculation (right). It is again seen that there are more extensive resonance structures in the $83 \mathrm{CC}$ NR case as compared to the 23-level BP case. From Table 3 of ZP1 the effective collision strengths for these four transitions are $0.58,1.344$, 1.067 and 1.096 respectively for $T=10000 \mathrm{~K}$ in the $83 \mathrm{CC}$ case, and are $0.435,1.099,0.702$ and 0.866 respectively in the 23-level BP calculation. Obviously these rate coefficients are enhanced even more by the resonances due to the much larger target expansion in the $83 \mathrm{CC}$ case, than for the transitions $3 d^{6}{ }^{5} \mathrm{D}_{4}-3 \mathrm{~d}^{6}{ }^{5} \mathrm{D}_{3,2,1,0}$.

Figure 2 shows the collision strengths for the optically allowed transitions $\mathrm{a}^{5} \mathrm{D}_{4}-\mathrm{z}^{5} \mathrm{P}_{3}^{\circ}, \mathrm{a}^{5} \mathrm{D}_{3}-\mathrm{z}^{5} \mathrm{P}_{2}^{\circ}$, and $\mathrm{a}^{5} \mathrm{D}_{2}-\mathrm{z}^{5} \mathrm{P}_{1}^{\circ}$. As mentioned earlier, the Coulomb-Bethe approximation was employed to estimate the contributions by higher partial waves. It is clear from the figure that resonances are not as strong as in the forbidden transitions and the rate coefficients will be dominated by the high energy region where the collision strength has the Bethe asysmptotic behavior, $\Omega \sim \ln (\epsilon)$.
The maxwellian averaged collision strength, or the effective collision strength, is given by:

$$
\Upsilon_{i j}=\int_{0}^{\infty} \Omega_{i j} \mathrm{e}^{-\epsilon_{j} / k T} \mathrm{~d}\left(\epsilon_{j} / k T\right) .
$$

Here $\Omega_{i j}$, the collision strength for excitation from level $i$ to level $j$, is averaged over a maxwellian distribution of incident electron energies $\epsilon_{j}$ above the excitation threshold of the level $j$, at temperature $T$. This slowly varying function of temperatures can then be used to obtain the rate coefficient, $q_{i j}$, for electron impact excitation,

$$
q_{i j}=\frac{8.6310^{-6}}{\sqrt{T} g_{i}} \mathrm{e}^{-E_{i j} / k T} \Upsilon_{i j} \quad\left(\mathrm{~cm}^{3} / \mathrm{s}\right)
$$

where $E_{i j}$ is the energy difference between levels $i$ and $j$ and $g_{i}$ is the statistical weight of level $i$.

Maxwellian averaged collision strengths for all 23871 transitions between 219 energy levels shown in Table 1 were calculated for 20 temperatures ranging from 1000 to $100000 \mathrm{~K}$. It should be noted that collision strengths for some of the transitions vanish due to a restriction on the quantum numbers of the initial and final levels, such as, for example, the large spin-change transitions between $\mathrm{a}^{5} \mathrm{D}_{\mathrm{J}}$ and $\mathrm{a}^{1} \mathrm{G}_{\mathrm{J}}$. Sample results of rate coefficients for transitions between the lowest 17 levels in Table 1 were given in ZP1 (Table 4). The entire dataset of 23871 effective collision strengths, tabulated in Table 2 at a wide mesh of temperatures in the above range, is only available in electronic form at the CDS or by writing to the author at: zhang@payne.mps.ohio-state.edu. 


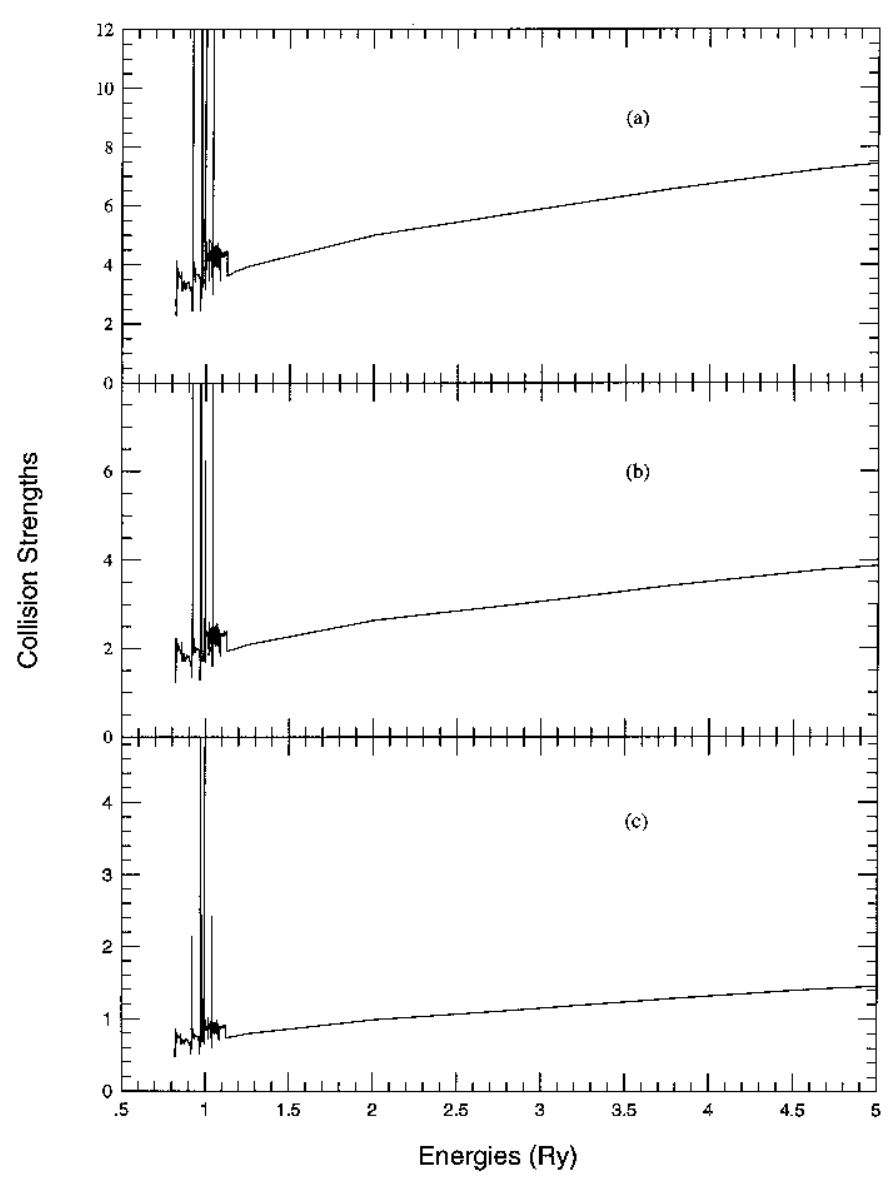

Fig. 2. The collision strengths for the optically allowed transitions a) $a^{5} \mathrm{D}_{4}-\mathrm{z}^{5} \mathrm{P}_{3}^{\circ}$, b) $\mathrm{a}^{5} \mathrm{D}_{3}-\mathrm{z}^{5} \mathrm{P}_{2}^{\circ}$, and c) $\mathrm{a}^{5} \mathrm{D}_{2}-\mathrm{z}^{5} \mathrm{P}_{1}^{\circ}$

\section{Discussion and conclusion}

In this section we give an estimate of the accuracy of the present data.

The fine $\nu$-mesh below $E=1.127 \mathrm{Ry}$, for excitation to the lower-lying, even-parity levels, fully resolves the important resonance features associated with the quintet and triplet odd-parity levels, up to the $\mathrm{x}^{5} \mathrm{P}_{\mathrm{J}}^{\circ}$ levels. Therefore, rate coefficients for this type of transitions should be highly accurate, $\approx 10-20 \%$. For optically allowed transitions from the $\mathrm{a}^{5} \mathrm{D}_{\mathrm{J}}$ levels to the quintet odd parity levels with energies below $1.127 \mathrm{Ry}$, the rate coefficients should also be of the same accuracy since resonances are relatively less important and the collision strengths are large and dominated by the higher partial waves, as seen from Fig. 2. For the forbidden (and inter-combination) transitions from the low-lying levels to intermediate energy levels, up to the $\mathrm{d}^{1} \mathrm{G}_{4}$ level, and transitions between these intermediate-energy levels, the accuracy of the rate coefficients is expected to be less, $\approx 30-50 \%$. For transitions corresponding to excitation to the high-lying levels with threshold energies greater than $1.127 \mathrm{Ry}$, the uncertainty could exceed $50 \%$ since an energy mesh was used and the resonances and coupling effects due to higher terms were omitted.

The present work will hopefully provide a reasonably complete collisional dataset for extensive astrophysical diagnostics of Fe III spectra from various sources.

Acknowledgements. The author wishes to thank Anil K. Pradhan for suggesting this work and for valuable discussions. This work was supported by a grant (PHY-9421898) from the U.S. National Science Foundation. The computational work was carried out on the Cray Y-MP8/64 and the massively parallel Cray T3D at the Ohio Supercomputer Center in Columbus, Ohio.

\section{References}

Berrington K.A., Zeippen C.J., Le Dourneuf M., Eissner W., Burk P.G., 1991, J. Phys. B 24, 3467

Eissner W., Jones M., Nussbaumer H., 1974, Comput. Phys. Comm. 8, 270

Garstang R.H., Robb W.D., Rountree S.P., 1978, ApJ 222, 384

Hummer D.G., Berrington K.A., Eissner W., Pradhan A.K, Saraph H.E., Tully J.A., 1993, A\&A 279, 298

Nahar S.N., Pradhan A.K., 1994, J. Phys. B 27, 429

Nahar S.N., Pradhan A.K., 1996, A\&A (the accompanying paper, Paper XVII)

Sugar J., Corliss C., 1985, J. Phys. Chem. Ref. Data 14, Suppl. 2

Zhang H.L., Pradhan A.K., 1995a, J. Phys. B 28, 3403 (ZP1)

Zhang H.L., Pradhan A.K., 1995b, J. Phys. B 28, L285

Zhang H.L., Pradhan A.K., 1995c, A\&A 293, 953 
Table 1. The 219 fine structure levels corresponding to the 83 LS terms included in the calculations and their observed energies (Ry) in Fe III (Sugar \& Corliss 1985). The empty entries in energies indicate the levels are not observed

\begin{tabular}{|c|c|c|c|c|c|c|c|c|c|}
\hline & Term & & $\mathrm{J}$ & Energy & & Term & & $\mathrm{J}$ & Energy \\
\hline 1 & $3 d^{6}$ & $a^{5} D$ & 4 & $0.0000 \mathrm{E}+00$ & 56 & $3 d^{5}\left({ }^{4} D\right) 4 s$ & $\mathrm{~b}^{3} \mathrm{D}$ & 1 & 7.0236E-01 \\
\hline 2 & & & 3 & $3.9749 \mathrm{E}-03$ & 57 & $3 d^{5}\left({ }^{2} I\right) 4 s$ & $a^{3} I$ & 7 & $7.2756 \mathrm{E}-01$ \\
\hline 3 & & & 2 & $6.7334 \mathrm{E}-03$ & 58 & & & 6 & $7.2760 \mathrm{E}-01$ \\
\hline 4 & & & 1 & 8.4967E-03 & 59 & & & 5 & $7.2774 \mathrm{E}-01$ \\
\hline 5 & & & 0 & $9.3614 \mathrm{E}-03$ & 60 & $3 d^{5}\left({ }^{6} S\right) 4 p$ & $\mathrm{z}^{7} \mathrm{P}^{\circ}$ & 4 & $7.5495 \mathrm{E}-01$ \\
\hline 6 & $3 d^{6}$ & $\mathrm{a}^{3} \mathrm{P}$ & 2 & $1.7683 \mathrm{E}-01$ & 61 & & & 3 & $7.5028 \mathrm{E}-01$ \\
\hline 7 & & & 1 & $1.8853 \mathrm{E}-01$ & 62 & & & 2 & $7.4725 \mathrm{E}-01$ \\
\hline 8 & & & 0 & $1.9327 \mathrm{E}-01$ & 63 & $3 d^{6}$ & $\mathrm{~b}^{1} \mathrm{D}$ & 2 & $7.0208 \mathrm{E}-01$ \\
\hline 9 & $3 d^{6}$ & $\mathrm{a}^{3} \mathrm{H}$ & 6 & $1.8272 \mathrm{E}-01$ & 64 & $3 d^{5}\left({ }^{2} \mathrm{D} 3\right) 4 \mathrm{~s}$ & $c^{3} \mathrm{D}$ & 3 & $7.5073 \mathrm{E}-01$ \\
\hline 10 & & & 5 & $1.8499 \mathrm{E}-01$ & 65 & & & 2 & $7.5098 \mathrm{E}-01$ \\
\hline 11 & & & 4 & $1.8664 \mathrm{E}-01$ & 66 & & & 1 & $7.5175 \mathrm{E}-01$ \\
\hline 12 & $3 d^{6}$ & $a^{3} \mathrm{~F}$ & 4 & $1.9558 \mathrm{E}-01$ & 67 & $3 \mathrm{~d}^{5}\left({ }^{4} \mathrm{~F} 3\right) 4 \mathrm{~s}$ & $a^{5} \mathrm{~F}$ & 5 & 7.5761E-01 \\
\hline 13 & & & 3 & $1.9774 \mathrm{E}-01$ & 68 & & & 4 & $7.5782 \mathrm{E}-01$ \\
\hline 14 & & & 2 & $1.9918 \mathrm{E}-01$ & 69 & & & 3 & $7.5852 \mathrm{E}-01$ \\
\hline 15 & $3 d^{6}$ & $a^{3} G$ & 5 & $2.2380 \mathrm{E}-01$ & 70 & & & 2 & $7.5962 \mathrm{E}-01$ \\
\hline 16 & & & 4 & $2.2728 \mathrm{E}-01$ & 71 & & & 1 & 7.6225E-01 \\
\hline 17 & & & 3 & $2.2911 \mathrm{E}-01$ & 72 & $3 d^{5}\left({ }^{2} \mathrm{I}\right) 4 \mathrm{~s}$ & $b^{1} \mathrm{I}$ & 6 & 7.6027E-01 \\
\hline 18 & $3 \mathrm{~d}^{5}\left({ }^{6} \mathrm{~S}\right) 4 \mathrm{~s}$ & $a^{7} \mathrm{~S}$ & 3 & $2.7419 \mathrm{E}-01$ & 73 & $3 \mathrm{~d}^{5}\left({ }^{2} \mathrm{~F} 2\right) 4 \mathrm{~s}$ & $c^{3} \mathrm{~F}$ & 4 & 7.6692E-01 \\
\hline 19 & $3 d^{6}$ & $r m a^{1} I$ & 6 & $2.7663 \mathrm{E}-01$ & 74 & & & 3 & 7.7159E-01 \\
\hline 20 & $3 d^{6}$ & $a^{3} D$ & 3 & $2.8120 \mathrm{E}-01$ & 75 & & & 2 & 7.6884E-01 \\
\hline 21 & & & 2 & $2.7991 \mathrm{E}-01$ & 76 & $3 d^{5}\left({ }^{2} \mathrm{D} 3\right) 4 \mathrm{~s}$ & $c^{1} D$ & 2 & $7.9141 \mathrm{E}-01$ \\
\hline 22 & & & 1 & $2.7999 \mathrm{E}-01$ & 77 & $3 d^{5}\left({ }^{2} \mathrm{~F} 2\right) 4 \mathrm{~s}$ & $\mathrm{~b}^{1} \mathrm{~F}$ & 3 & $8.0102 \mathrm{E}-01$ \\
\hline 23 & $3 d^{6}$ & $a^{1} G$ & 4 & $2.8146 \mathrm{E}-01$ & 78 & $3 \mathrm{~d}^{5}\left({ }^{2} \mathrm{H}\right) 4 \mathrm{~s}$ & $b^{3} \mathrm{H}$ & 6 & $8.1033 \mathrm{E}-01$ \\
\hline 24 & $3 d^{6}$ & $\mathrm{a}^{1} \mathrm{~S}$ & 0 & 3.1723E-01 & 79 & & & 5 & $8.0825 \mathrm{E}-01$ \\
\hline 25 & $3 d^{6}$ & $a^{1} D$ & 2 & $3.2627 \mathrm{E}-01$ & 80 & & & 4 & $8.0796 \mathrm{E}-01$ \\
\hline 26 & $3 d^{5}\left({ }^{6} \mathrm{~S}\right) 4 \mathrm{~s}$ & $a^{5} \mathrm{~S}$ & 2 & $3.7362 \mathrm{E}-01$ & 81 & $3 d^{5}\left({ }^{6} \mathrm{~S}\right) 4 \mathrm{p}$ & $\mathrm{z}^{5} \mathrm{P}^{\circ}$ & 3 & $8.1180 \mathrm{E}-01$ \\
\hline 27 & $3 d^{6}$ & $\mathrm{a}^{1} \mathrm{~F}$ & 3 & $3.9091 \mathrm{E}-01$ & 82 & & & 2 & $8.1408 \mathrm{E}-01$ \\
\hline 28 & $3 d^{6}$ & $b^{3} \mathrm{P}$ & 2 & 4.5939E-01 & 83 & & & 1 & $8.1551 \mathrm{E}-01$ \\
\hline 29 & & & 1 & $4.5178 \mathrm{E}-01$ & 84 & $3 d^{5}\left({ }^{2} G 2\right) 4 s$ & $c^{3} \mathrm{G}$ & 5 & 8.1930E-01 \\
\hline 30 & & & 0 & $4.4787 \mathrm{E}-01$ & 85 & & & 4 & 8.1817E-01 \\
\hline 31 & $3 d^{6}$ & $b^{3} \mathrm{~F}$ & 4 & $4.5815 \mathrm{E}-01$ & 86 & & & 3 & $8.1738 \mathrm{E}-01$ \\
\hline 32 & & & 3 & $4.5832 \mathrm{E}-01$ & 87 & $3 d^{5}\left({ }^{4} F\right) 4 s$ & $d^{3} F$ & 4 & $8.2445 \mathrm{E}-01$ \\
\hline 33 & & & 2 & $4.5732 \mathrm{E}-01$ & 88 & & & 3 & $8.2455 \mathrm{E}-01$ \\
\hline 34 & $3 d^{6}$ & $b^{1} G$ & 4 & $5.2144 \mathrm{E}-01$ & 89 & & & 2 & 8.2400E-01 \\
\hline 35 & $3 \mathrm{~d}^{5}\left({ }^{4} \mathrm{G}\right) 4 \mathrm{~s}$ & $a^{5} G$ & 6 & $5.7797 \mathrm{E}-01$ & 90 & $3 d^{5}\left({ }^{2} H\right) 4 s$ & $a^{1} \mathrm{H}$ & 5 & $8.4314 \mathrm{E}-01$ \\
\hline 36 & & & 5 & $5.7835 \mathrm{E}-01$ & 91 & $3 d^{5}\left({ }^{2} \mathrm{~F} 1\right) 4 \mathrm{~s}$ & $e^{3} F$ & 4 & $8.5102 \mathrm{E}-01$ \\
\hline 37 & & & 4 & $5.7853 \mathrm{E}-01$ & 92 & & & 3 & $8.5105 \mathrm{E}-01$ \\
\hline 38 & & & 3 & $5.7860 \mathrm{E}-01$ & 93 & & & 2 & 8.5124E-01 \\
\hline 39 & & & 2 & $5.7861 \mathrm{E}-01$ & 94 & $3 \mathrm{~d}^{5}\left({ }^{2} \mathrm{G} 2\right) 4 \mathrm{~s}$ & $c^{1} G$ & 4 & $8.5215 \mathrm{E}-01$ \\
\hline 40 & $3 \mathrm{~d}^{5}\left({ }^{4} \mathrm{P}\right) 4 \mathrm{~s}$ & $\mathrm{a}^{5} \mathrm{P}$ & 3 & 6.0567E-01 & 95 & $3 d^{5}\left({ }^{2} \mathrm{~F} 1\right) 4 \mathrm{~s}$ & $c^{1} \mathrm{~F}$ & 3 & 8.8431E-01 \\
\hline 41 & & & 2 & $6.0620 \mathrm{E}-01$ & 96 & $3 d^{6}$ & $\mathrm{~b}^{1} \mathrm{~S}$ & 0 & 9.3323E-01 \\
\hline 42 & & & 1 & $6.0683 \mathrm{E}-01$ & 97 & $3 \mathrm{~d}^{5}\left({ }^{2} \mathrm{~S}\right) 4 \mathrm{~s}$ & $a^{3} \mathrm{~S}$ & 1 & 8.9908E-01 \\
\hline 43 & $3 \mathrm{~d}^{5}\left({ }^{4} \mathrm{D}\right) 4 \mathrm{~s}$ & $b^{5} \mathrm{D}$ & 4 & $6.3511 \mathrm{E}-01$ & 98 & $3 d^{5}\left({ }^{2} \mathrm{D} 2\right) 4 \mathrm{~s}$ & $d^{3} \mathrm{D}$ & 3 & $9.6530 \mathrm{E}-01$ \\
\hline 44 & & & 3 & $6.3640 \mathrm{E}-01$ & 99 & & & 2 & $9.6509 \mathrm{E}-01$ \\
\hline 45 & & & 2 & $6.3641 \mathrm{E}-01$ & 100 & & & 1 & 9.6499E-01 \\
\hline 46 & & & 1 & $6.3596 \mathrm{E}-01$ & 101 & $3 \mathrm{~d}^{5}\left({ }^{2} \mathrm{D} 2\right) 4 \mathrm{~s}$ & $d^{1} D$ & 2 & $9.9848 \mathrm{E}-01$ \\
\hline 47 & & & 0 & $6.3559 \mathrm{E}-01$ & 102 & $3 d^{5}\left({ }^{4} G\right) 4 p$ & $z^{5} G^{\circ}$ & 6 & $1.0365 \mathrm{E}+00$ \\
\hline 48 & $3 d^{5}\left({ }^{4} G\right) 4 s$ & $b^{3} G$ & 5 & $6.4421 \mathrm{E}-01$ & 103 & & & 5 & $1.0359 \mathrm{E}+00$ \\
\hline 49 & & & 4 & $6.4453 \mathrm{E}-01$ & 104 & & & 4 & $1.0355 \mathrm{E}+00$ \\
\hline 50 & & & 3 & $6.4449 \mathrm{E}-01$ & 105 & & & 3 & $1.0352 \mathrm{E}+00$ \\
\hline 51 & $3 \mathrm{~d}^{5}\left({ }^{4} \mathrm{P}\right) 4 \mathrm{~s}$ & $c^{3} \mathrm{P}$ & 2 & $6.7186 \mathrm{E}-01$ & 106 & & & 2 & $1.0351 \mathrm{E}+00$ \\
\hline 52 & & & 1 & $6.7296 \mathrm{E}-01$ & 107 & $3 d^{5}\left({ }^{2} S\right) 4 s$ & $c^{1} \mathrm{~S}$ & 0 & $1.0372 \mathrm{E}+00$ \\
\hline 53 & & & 0 & $6.7375 \mathrm{E}-01$ & 108 & $3 d^{5}\left({ }^{2} \mathrm{G} 1\right) 4 \mathrm{~s}$ & $d^{3} G$ & 5 & $1.0418 \mathrm{E}+00$ \\
\hline 54 & $3 \mathrm{~d}^{5}\left({ }^{4} \mathrm{D}\right) 4 \mathrm{~s}$ & $b^{3} \mathrm{D}$ & 3 & $7.0128 \mathrm{E}-01$ & 109 & & & 4 & $1.0419 \mathrm{E}+00$ \\
\hline 55 & & & 2 & 7.0261E-01 & 110 & & & 3 & $1.0421 \mathrm{E}+00$ \\
\hline
\end{tabular}


Table 1. continued

\begin{tabular}{|c|c|c|c|c|c|c|c|c|c|}
\hline & Term & & $\mathrm{J}$ & Energy & & Term & & $\mathrm{J}$ & Energy \\
\hline$\overline{111}$ & $3 d^{5}\left({ }^{4} G\right) 4 p$ & $\mathrm{z}^{5} \mathrm{H}^{0}$ & 7 & $1.0538 \mathrm{E}+00$ & 166 & $3 d^{5}\left({ }^{4} D\right) 4 p$ & $\mathrm{y}^{3} \mathrm{P}^{0}$ & 2 & $1.1748 \mathrm{E}+00$ \\
\hline 112 & & & 6 & $1.0523 \mathrm{E}+00$ & 167 & & & 1 & $1.1719 \mathrm{E}+00$ \\
\hline 113 & & & 5 & $1.0506 \mathrm{E}+00$ & 168 & & & 0 & $1.1698 \mathrm{E}+00$ \\
\hline 114 & & & 4 & $1.0490 \mathrm{E}+00$ & 169 & $3 d^{5}\left({ }^{2} \mathrm{I}\right) 4 \mathrm{p}$ & $z^{3} K^{\circ}$ & 8 & $1.1924 \mathrm{E}+00$ \\
\hline 115 & & & 3 & $1.0475 \mathrm{E}+00$ & 170 & & & 7 & $1.1850 \mathrm{E}+00$ \\
\hline 116 & $3 d^{5}\left({ }^{4} G\right) 4 p$ & $\mathrm{z}^{5} \mathrm{~F}^{\circ}$ & 5 & $1.0600 \mathrm{E}+00$ & 171 & & & 6 & $1.1833 \mathrm{E}+00$ \\
\hline 117 & & & 4 & $1.0613 \mathrm{E}+00$ & 172 & $3 d^{5}\left({ }^{2} I\right) 4 p$ & $z^{3} I^{\circ}$ & 7 & $1.1941 \mathrm{E}+00$ \\
\hline 118 & & & 3 & $1.0614 \mathrm{E}+00$ & 173 & & & 6 & $1.1915 \mathrm{E}+00$ \\
\hline 119 & & & 2 & $1.0660 \mathrm{E}+00$ & 174 & & & 5 & $1.1870 \mathrm{E}+00$ \\
\hline 120 & & & 1 & $1.0656 \mathrm{E}+00$ & 175 & $3 d^{5}\left({ }^{2} I\right) 4 p$ & $\mathrm{z}^{1} \mathrm{H}^{\circ}$ & 5 & $1.2002 \mathrm{E}+00$ \\
\hline 121 & $3 d^{5}\left({ }^{4} \mathrm{P}\right) 4 \mathrm{p}$ & $\mathrm{z}^{5} \mathrm{~S}^{\circ}$ & 2 & $1.0653 \mathrm{E}+00$ & 176 & $3 d^{5}\left({ }^{2} I\right) 4 p$ & $z^{1} K^{\circ}$ & 7 & $1.2028 \mathrm{E}+00$ \\
\hline 122 & $3 d^{5}\left({ }^{4} \mathrm{P}\right) 4 \mathrm{p}$ & $\mathrm{z}^{5} \mathrm{D}^{\circ}$ & 4 & $1.0709 \mathrm{E}+00$ & 177 & $3 \mathrm{~d}^{5}\left({ }^{2} \mathrm{D}\right) 4 \mathrm{p}$ & $\mathrm{x}^{3} \mathrm{~F}^{\circ}$ & 4 & $1.2100 \mathrm{E}+00$ \\
\hline 123 & & & 3 & $1.0668 \mathrm{E}+00$ & 178 & & & 3 & $1.2036 \mathrm{E}+00$ \\
\hline 124 & & & 2 & $1.0609 \mathrm{E}+00$ & 179 & & & 2 & $1.2038 \mathrm{E}+00$ \\
\hline 125 & & & 1 & $1.0605 \mathrm{E}+00$ & 180 & $3 d^{5}\left({ }^{2} \mathrm{I}\right) 4 \mathrm{p}$ & $\mathrm{y}^{3} \mathrm{H}^{\circ}$ & 6 & $1.2053 \mathrm{E}+00$ \\
\hline 126 & & & 0 & $1.0604 \mathrm{E}+00$ & 181 & & & 5 & $1.2080 \mathrm{E}+00$ \\
\hline 127 & $3 d^{5}\left({ }^{2} \mathrm{G} 1\right) 4 \mathrm{~s}$ & $d^{1} G$ & 4 & $1.0748 \mathrm{E}+00$ & 182 & & & 4 & $1.2089 \mathrm{E}+00$ \\
\hline 128 & $3 d^{5}\left({ }^{4} G\right) 4 p$ & $\mathrm{z}^{3} \mathrm{~F}^{\circ}$ & 4 & $1.0785 \mathrm{E}+00$ & 183 & $3 \mathrm{~d}^{5}\left({ }^{2} \mathrm{D}\right) 4 \mathrm{p}$ & $\mathrm{z}^{1} \mathrm{D}^{\circ}$ & 2 & $1.1978 \mathrm{E}+00$ \\
\hline 129 & & & 3 & $1.0775 \mathrm{E}+00$ & 184 & $3 \mathrm{~d}^{5}\left({ }^{2} \mathrm{D}\right) 4 \mathrm{p}$ & $\mathrm{x}^{3} \mathrm{P}^{\circ}$ & 2 & $1.2235 \mathrm{E}+00$ \\
\hline 130 & & & 2 & $1.0768 \mathrm{E}+00$ & 185 & & & 1 & $1.2261 \mathrm{E}+00$ \\
\hline 131 & $3 d^{5}\left({ }^{4} G\right) 4 p$ & $\mathrm{z}^{3} \mathrm{H}^{\circ}$ & 6 & $1.0785 \mathrm{E}+00$ & 186 & & & 0 & $1.2310 \mathrm{E}+00$ \\
\hline 132 & & & 5 & $1.0804 \mathrm{E}+00$ & 187 & $3 d^{5}\left({ }^{2} F\right) 4 p$ & $z^{1} G^{\circ}$ & 4 & $1.2244 \mathrm{E}+00$ \\
\hline 133 & & & 4 & $1.0815 \mathrm{E}+00$ & 188 & $3 d^{5}\left({ }^{2} F\right) 4 p$ & $\mathrm{y}^{3} \mathrm{G}^{\circ}$ & 5 & $1.2331 \mathrm{E}+00$ \\
\hline 134 & $3 d^{5}\left({ }^{4} \mathrm{P}\right) 4 \mathrm{p}$ & $\mathrm{y}^{5} \mathrm{P}^{\circ}$ & 3 & $1.0793 \mathrm{E}+00$ & 189 & & & 4 & $1.2353 \mathrm{E}+00$ \\
\hline 135 & & & 2 & $1.0819 \mathrm{E}+00$ & 190 & & & 3 & $1.2261 \mathrm{E}+00$ \\
\hline 136 & & & 1 & $1.0832 \mathrm{E}+00$ & 191 & $3 d^{5}\left({ }^{4} F\right) 4 p$ & $\mathrm{y}^{5} \mathrm{G}^{\circ}$ & 6 & $1.2355 \mathrm{E}+00$ \\
\hline 137 & $3 d^{5}\left({ }^{4} \mathrm{P}\right) 4 \mathrm{p}$ & $\mathrm{z}^{3} \mathrm{P}^{\circ}$ & 2 & $1.0908 \mathrm{E}+00$ & 192 & & & 5 & $1.2369 \mathrm{E}+00$ \\
\hline 138 & & & 1 & $1.0934 \mathrm{E}+00$ & 193 & & & 4 & $1.2324 \mathrm{E}+00$ \\
\hline 139 & & & 0 & $1.0952 \mathrm{E}+00$ & 194 & & & 3 & $1.2311 \mathrm{E}+00$ \\
\hline 140 & $3 d^{5}\left({ }^{4} \mathrm{D}\right) 4 \mathrm{p}$ & $\mathrm{y}^{5} \mathrm{~F}^{\circ}$ & 5 & $1.1069 \mathrm{E}+00$ & 195 & & & 2 & $1.2296 \mathrm{E}+00$ \\
\hline 141 & & & 4 & $1.1048 \mathrm{E}+00$ & 196 & $3 d^{5}\left({ }^{2} D\right) 4 p$ & $x^{3} D^{\circ}$ & 3 & $1.2300 \mathrm{E}+00$ \\
\hline 142 & & & 3 & $1.1027 \mathrm{E}+00$ & 197 & & & 2 & $1.2328 \mathrm{E}+00$ \\
\hline 143 & & & 2 & $1.1010 \mathrm{E}+00$ & 198 & & & 1 & $1.2322 \mathrm{E}+00$ \\
\hline 144 & & & 1 & $1.0999 \mathrm{E}+00$ & 199 & $3 d^{5}\left(a^{2} F\right) 4 p$ & $\mathrm{w}^{3} \mathrm{D}^{\circ}$ & 3 & $1.2366 \mathrm{E}+00$ \\
\hline 145 & $3 d^{5}\left({ }^{4} G\right) 4 p$ & $\mathrm{z}^{3} \mathrm{G}^{\circ}$ & 5 & $1.1113 \mathrm{E}+00$ & 200 & & & 2 & $1.2466 \mathrm{E}+00$ \\
\hline 146 & & & 4 & $1.1112 \mathrm{E}+00$ & 201 & & & 1 & $1.2436 \mathrm{E}+00$ \\
\hline 147 & & & 3 & $1.1110 \mathrm{E}+00$ & 202 & $3 d^{5}\left({ }^{2} \mathrm{I}\right) 4 \mathrm{p}$ & $z^{1} I^{\circ}$ & 6 & $1.2369 \mathrm{E}+00$ \\
\hline 148 & $3 d^{5}\left({ }^{4} P\right) 4 p$ & $\mathrm{z}^{3} \mathrm{D}^{\circ}$ & 3 & $1.1149 \mathrm{E}+00$ & 203 & $3 d^{5}\left({ }^{2} \mathrm{D}\right) 4 \mathrm{p}$ & $\mathrm{z}^{1} \mathrm{~F}^{\circ}$ & 3 & $1.2411 \mathrm{E}+00$ \\
\hline 149 & & & 2 & $1.1175 \mathrm{E}+00$ & 204 & $3 d^{5}\left({ }^{4} F\right) 4 p$ & $\mathrm{x}^{5} \mathrm{~F}^{\circ}$ & 5 & $1.2410 \mathrm{E}+00$ \\
\hline 150 & & & 1 & $1.1194 \mathrm{E}+00$ & 205 & & & 4 & $1.2392 \mathrm{E}+00$ \\
\hline 151 & $3 d^{5}\left({ }^{4} D\right) 4 p$ & $\mathrm{y}^{5} \mathrm{D}^{\circ}$ & 4 & $1.1203 \mathrm{E}+00$ & 206 & & & 3 & $1.2394 \mathrm{E}+00$ \\
\hline 152 & & & 3 & & 207 & & & 2 & $1.2404 \mathrm{E}+00$ \\
\hline 153 & & & 2 & & 208 & & & 1 & $1.2415 \mathrm{E}+00$ \\
\hline 154 & & & 1 & & 209 & $3 d^{5}\left(a^{2} F\right) 4 p$ & $\mathrm{w}^{3} \mathrm{~F}^{\circ}$ & 4 & $1.2449 \mathrm{E}+00$ \\
\hline 155 & & & 0 & $1.1250 \mathrm{E}+00$ & 210 & & & 3 & $1.2466 \mathrm{E}+00$ \\
\hline 156 & $3 d^{5}\left({ }^{4} D\right) 4 p$ & $\mathrm{x}^{5} \mathrm{P}^{\circ}$ & 3 & $1.1277 \mathrm{E}+00$ & 211 & & & 2 & $1.2442 \mathrm{E}+00$ \\
\hline 157 & & & 2 & $1.1272 \mathrm{E}+00$ & 212 & $3 d^{5}\left({ }^{4} F\right) 4 p$ & $x^{5} D^{\circ}$ & 4 & $1.2503 \mathrm{E}+00$ \\
\hline 158 & & & 1 & $1.1259 \mathrm{E}+00$ & 213 & & & 3 & $1.2523 \mathrm{E}+00$ \\
\hline 159 & $3 d^{5}\left({ }^{4} D\right) 4 p$ & $\mathrm{y}^{3} \mathrm{D}^{\circ}$ & 3 & $1.1378 \mathrm{E}+00$ & 214 & & & 2 & $1.2534 \mathrm{E}+00$ \\
\hline 160 & & & 2 & $1.1382 \mathrm{E}+00$ & 215 & & & 1 & $1.2535 \mathrm{E}+00$ \\
\hline 161 & & & 1 & $1.1387 \mathrm{E}+00$ & 216 & & & 0 & $1.2537 \mathrm{E}+00$ \\
\hline 162 & $3 d^{5}\left({ }^{4} D\right) 4 p$ & $\mathrm{y}^{3} \mathrm{~F}^{\circ}$ & 4 & $1.1431 \mathrm{E}+00$ & 217 & $3 \mathrm{~d}^{5}\left({ }^{2} \mathrm{H}\right) 4 \mathrm{p}$ & $\mathrm{x}^{3} \mathrm{H}^{\circ}$ & 6 & $1.2600 \mathrm{E}+00$ \\
\hline 163 & & & 3 & $1.1449 \mathrm{E}+00$ & 218 & & & 5 & $1.2554 \mathrm{E}+00$ \\
\hline 164 & & & 2 & $1.1452 \mathrm{E}+00$ & 219 & & & 4 & $1.2532 \mathrm{E}+00$ \\
\hline 165 & $3 \mathrm{~d}^{5}\left({ }^{4} \mathrm{P}\right) 4 \mathrm{p}$ & $\mathrm{z}^{3} \mathrm{~S}^{\circ}$ & 1 & $1.1518 \mathrm{E}+00$ & & & & & \\
\hline
\end{tabular}

